(c) American Dairy Science Association, 2005.

\title{
Genetic Evaluation of Calving Ease for Brown Swiss and Jersey Bulls from Purebred and Crossbred Calvings
}

\author{
J. B. Cole, R. C. Goodling, Jr., G. R. Wiggans, and P. M. VanRaden \\ Animal Improvement Programs Laboratory, Agricultural Research Service, USDA, \\ Beltsville, MD 20705-2350
}

\begin{abstract}
The objective of this study was to examine the feasibility of implementing routine national calving ease (CE) genetic evaluations of Brown Swiss (BS) and Jersey (JE) sires that include records of crossbred calvings. Records were available for 11,793 BS calvings, 3431 BS-sired crosses, 65,293 JE calvings, and $7090 \mathrm{JE}$-sired crosses. Evaluations were performed for each breed using only purebred calvings and using both purebred and crossbred calvings. In the latter evaluations, the sire-maternal grandsire model used for the routine evaluation of Holstein (HO) CE was modified to include a fixed breed composition effect to account for differences between purebred and crossbred calvings. Jersey cows had very little calving difficulty $(0.5$ to $0.7 \%)$ and JE bulls had a very small range of evaluations, suggesting that a routine JE evaluation would be of little value. Results from the BS evaluations suggest a routine evaluation would provide BS breeders with a useful tool for genetic improvement. Further examination of data showed that many BS calvings were in mixed herds with $\mathrm{HO}$ calvings. As a result, a joint evaluation for BS and HO bulls was developed. The BS data showed that there is similar genetic variability as found in the HO population, which suggests implementation of a routine evaluation including BS CE would be of value. It appears BS bulls may produce daughters with superior maternal calving ability compared with HO. Validation of the joint evaluation was performed by comparing results with the routine $\mathrm{HO}$ evaluation. Holstein solutions from the joint evaluation were comparable to results from the routine HO-only evaluation. Correlations among solutions and evaluations showed HO evaluations were not adversely affected by BS data and BS sires were reranked as compared with the BSonly evaluation.
\end{abstract}

(Key words: calving ease, crossbred, genetic evaluation, purebred)

Received September 30, 2004.

Accepted December 19, 2004.

Corresponding author: J. B. Cole; e-mail: jcole@aipl.arsusda.gov.
Abbreviation key: $\mathbf{B H}=$ dataset with BS-sired purebred calvings, HO-sired purebred calvings, and BSsired calvings from $\mathrm{HO}$ dams, $\mathbf{B S}=$ Brown Swiss, $\mathbf{B S}_{\mathbf{c}}=$ dataset with all calvings in $\mathrm{BS}_{\mathrm{p}}$ plus $\mathrm{BS}$-sired crossbred calvings, $\mathbf{B S}_{\mathbf{p}}=$ dataset with BS-sired purebred calvings, $\mathbf{C E}=$ calving ease, $\% \mathbf{D B H}=$ percentage of difficult births in heifers, DCE = daughter calving ease, $\mathbf{H O}=$ Holstein, $\mathbf{J E}=$ Jersey, $\mathbf{J E}_{\mathbf{c}}=$ dataset with all calvings in $\mathrm{JE}_{\mathrm{p}}$ plus $\mathrm{JE}$-sired crossbred calvings, $\mathbf{J E}_{\mathbf{p}}=$ dataset with JE-sired purebred calvings, MGS = maternal grandsire, $\mathbf{S C E}=$ service-sire calving ease, $\mathbf{S - M G S ~ = ~}$ sire-maternal grandsire.

\section{INTRODUCTION}

The Animal Improvement Programs Laboratory of USDA-ARS performs national genetic evaluations for calving ease (CE) twice a year and maintains the associated database. In 2003, a sire-maternal grandsire (SMGS) threshold model (Van Tassell et al., 2003) replaced the sire threshold model (Berger, 1994) used since 1988. Genetic evaluations of calving ease have been provided for US Holsteins (HO) since 1978 (Berger, 1994).

Dairy producers are increasingly interested in crossbreeding. In a recent survey of US dairy producers using crossbreeding, almost all respondents indicated a desire to improve calving ease as well as health, fertility, and longevity (Weigel and Barlass, 2003). Holstein-Brown Swiss (BS) and HO-Jersey (JE) $\mathrm{F}_{1}$ both outperformed purebred HO for Net Merit and Cheese Merit, although no cross outperformed HO for Fluid Merit (VanRaden and Sanders, 2003). The authors also reported a small, favorable (1.2\%) heterotic benefit for productive life. Heins et al. (2003b) reported that JE-HO crossbred heifers and cows had significantly lower phenotypic dystocia scores than purebred HO contemporaries, $1.32 \mathrm{vs.}$ 1.94. A related study (Heins et al., 2003a) reported that JE-sired calves were born with significantly lower dystocia scores than BS-sired calves, and BS-sired calves had significantly lower dystocia scores than HOsired calves in a population of HO, HO-JE, and HONormande cows. McClintock et al. (2004) presented further evidence that JE-HO crossbreds have a lower inci- 
dence of dystocia than purebred HO. No difference for dystocia was found between HO-JE and JE-HO calvings (Cassell et al., 2004), although the sample size was very small. Heins et al. (2004) reported that HO-sired calvings had significantly more dystocia than JE-sired calvings; HO cows also had higher rates of dystocia than Normande-HO, Montbeliarde-HO, and ScandinavianHO cows. These results suggest that the use of sires from several non-HO breeds in a crossbreeding program may result in reduced incidence of dystocia.

In response to interest in calving ease from the Brown Swiss Association and the announcement of an Interbull pilot study of $\mathrm{CE}$ for breeds other than $\mathrm{HO}$, the Animal Improvement Programs Laboratory studied CE in the BS and JE breeds. The objectives of this research were: 1) to determine the extent to which CE data are recorded in the $\mathrm{BS}$ and JE breeds; 2) to characterize the available CE data for BS and JE, as well as for BS- and JE-sired crosses; 3) to perform preliminary prediction of PTA for these breeds, as well as for BSand JE-sired crosses, using the available data; and 4) to develop a procedure for routine national evaluations for the BS and JE breeds, if appropriate.

\section{MATERIALS AND METHODS}

\section{Data}

Calving ease records for BS- and JE-sired pure- and crossbred calvings were extracted from the Animal Improvement Programs Laboratory database. Purebred calvings were defined as calvings with matching sire and dam breed codes; sire and dam breed codes differed for crossbred calvings. All records were subjected to a series of data quality edits (Van Tassell et al., 2003). Four datasets were created for use in breeding value estimation: BS-sired purebred calvings $\left(\mathbf{B S}_{\mathbf{p}}\right)$; all calvings in $\mathrm{BS}_{\mathrm{p}}$ plus BS-sired crossbred calvings $\left(\mathbf{B S}_{\mathbf{c}}\right)$; JEsired purebred calvings $\left(\mathbf{J E}_{\mathbf{p}}\right)$; and all calvings in $\mathrm{JE}_{\mathrm{p}}$ plus JE-sired crossbred calvings $\left(\mathbf{J E}_{\mathbf{c}}\right)$. A fifth dataset was created for use in the routine BS evaluation; it was formed by combining BS-sired purebred calvings, HOsired purebred calvings, and BS-sired calvings from $\mathrm{HO}$ dams (BH). In addition, results of the routine $\mathrm{HO}$ evaluation were used to validate the results from the $\mathrm{BH}$ evaluation.

Difficult births, indicated by a CE score of 4 or 5 , were combined into a single category for the $\mathrm{JE}_{\mathrm{p}}$ and $\mathrm{JE}_{\mathrm{c}}$ evaluations to attain convergence. Records from herds with only difficult calvings, or with only one calving record in the database, were omitted from the BS and JE datasets.

\section{Genetic Evaluation Models}

Purebred and crossbred evaluation. The same SMGS model as used for the routine $\mathrm{HO}$ genetic evaluation (Van Tassell et al., 2003) was used to analyze $\mathrm{BS}_{\mathrm{p}}$ and $\mathrm{JE}_{\mathrm{p}}$ datasets:

$$
\begin{gathered}
\mathrm{y}_{\mathrm{ijk} k n o p r}=\mathrm{hy}_{\mathrm{i}}+\mathrm{YS}_{\mathrm{j}}+\mathrm{PS}_{\mathrm{k}}+\mathrm{SB}_{\mathrm{l}} \\
+\mathrm{BM}_{\mathrm{n}}+\mathrm{S}_{\mathrm{lo}}+\mathrm{m}_{\mathrm{np}}+\mathrm{e}_{\mathrm{ijkln} \mathrm{kpr}}
\end{gathered}
$$

where $\mathrm{y}_{\mathrm{ijk} \text { lnopr }}=\mathrm{CE}$ score, $\mathrm{hy}_{\mathrm{i}}=$ random effect of herdyear $\mathrm{i}, \mathrm{YS}_{\mathrm{j}}=$ fixed effect of year-season $\mathrm{j}, \mathrm{PS}_{\mathrm{k}}=$ fixed effect of parity-sex $\mathrm{k}, \mathrm{SB}_{1}=$ fixed effect of sire birth year $1, \mathrm{BM}_{\mathrm{n}}=$ fixed effect of maternal grandsire (MGS) birth year $\mathrm{n}, \mathrm{s}_{\mathrm{lo}}=$ random effect of sire $\mathrm{o}$ in birth-year group $\mathrm{l}, \mathrm{m}_{\mathrm{np}}=$ random effect of MGS $\mathrm{n}$ in birth-year group $\mathrm{p}$, and $\mathrm{e}_{\mathrm{ijklnopr}}=$ random residual effect.

Parities were first, second, and third and later. Yearseason groups begin in October and May. The model used to analyze $\mathrm{BS}_{\mathrm{c}}, \mathrm{JE}_{\mathrm{c}}$, and $\mathrm{BH}$ datasets was similar to [1] but included a fixed effect to account for breed composition $\left(\mathrm{BC}_{\mathrm{q}}\right)$. The breed composition effect had 2 levels in the $\mathrm{BS}_{\mathrm{c}}\left(\mathrm{JE}_{\mathrm{c}}\right)$ data set to differentiate between births of purebred and crossbred calves. There were 3 levels of breed composition in the $\mathrm{BH}$ data set to differentiate between breeds of MGS (BS, HO, and all other). The (co)variance components estimated by Wiggans et al. (2003) were used for all analyses.

The same sire birth-year groups were defined for the $\mathrm{BS}_{\mathrm{p}}\left(\mathrm{JE}_{\mathrm{p}}\right)$ and $\mathrm{BS}_{\mathrm{c}}\left(\mathrm{JE}_{\mathrm{c}}\right)$ datasets: $\leq 1990,1991$ to 1995 , and 1996, 1997, ..., 2003. Identical MGS birth-year group definitions were used for the $\mathrm{BS}_{\mathrm{p}}\left(\mathrm{JE}_{\mathrm{p}}\right)$ datasets. Maternal grandsire birth years ranged from 1964 to 2001 for BS and 1958 to 2001 for JE. Different MGS groupings for animals with known MGS ID and with unknown MGS ID were used. For animals with known MGS ID, MGS birth years were $\leq 1985,1986$ to 1990 , 1991 to 1995 , and 1996, and 1997 for $\mathrm{BS}_{\mathrm{c}}$ and $\leq 1990$, 1991 to 1995 , and 1996 to 2000 for $\mathrm{JE}_{\mathrm{c}}$. Records without valid MGS ID were assigned to birth-year groups based on dam birth year. When dam birth years were not recorded, they were approximated as calving year parity - 1. Maternal grandsire birth-year groups for bulls without valid ID were: $\leq 1995$ and $>1995$.

Genetic bases for service-sire CE (SCE) and daughter CE (DCE) were defined by bulls born in 1995 and in 1990, respectively. Sire and MGS solutions on the underlying scale were adjusted such that the mean of the base bulls on the observed scale was approximately equal to the mean percentage of difficult births in heifers (\%DBH; CE scores of 4 or 5 for first-calf heifers giving birth to male calves) observed in the appropriate offspring (Van Tassell et al., 2003). Mean \%DBH was estimated separately for each data set. The $\mathrm{BH}$ evalua- 
Table 1. Distribution of calving ease scores in the Brown Swiss, Jersey, and Brown Swiss-Holstein datasets.

\begin{tabular}{llllllc}
\hline & \multicolumn{5}{c}{ Frequency $^{2}$} & \\
\cline { 2 - 6 } Dataset $^{1}$ & 1 & 2 & 3 & 4 & 5 & $\begin{array}{c}\text { Records used for } \\
\text { genetic evaluation }\end{array}$ \\
\hline $\mathrm{BS}_{\mathrm{p}}$ & 84.6 & 7.2 & 4.6 & 1.7 & 1.9 & 11,793 \\
$\mathrm{BS}_{\mathrm{c}}$ & 82.1 & 8.5 & 5.3 & 1.9 & 2.1 & 15,224 \\
$\mathrm{JE}_{\mathrm{p}}$ & 95.7 & 2.9 & 0.8 & 0.2 & 0.3 & 65,293 \\
$\mathrm{JE}_{\mathrm{c}}$ & 94.7 & 3.4 & 1.2 & 0.4 & 0.3 & 72,383 \\
$\mathrm{BH}$ & 75.3 & 11.1 & 9.2 & 2.9 & 1.5 & $12,095,614$ \\
\hline
\end{tabular}

${ }^{1} \mathrm{BS}_{\mathrm{p}}\left(\mathrm{JE}_{\mathrm{p}}\right)=$ Brown Swiss (Jersey) purebred cows only; $\mathrm{BS}_{\mathrm{c}}\left(\mathrm{JE}_{\mathrm{c}}\right)=$ Brown Swiss (Jersey) purebred and crossbred calvings; $\mathrm{BH}=$ Brown Swiss purebred cows, HO purebred cows, and BS-HO crossbred cows.

${ }^{2}$ Calving ease scores are: $1=$ no problem, $2=$ slight problem, $3=$ needed assistance, $4=$ considerable force, 5 = extreme difficulty. Calving ease scores of 4 and 5 were combined into a single score of 4 for each Jersey evaluation.

tion used the HO base for all animals although mean $\% \mathrm{DBH}$ was slightly higher for HO than BS (8.1 vs. 7.6\%). The choice of base does not affect within-breed rankings.

Joint Brown Swiss-Holstein evaluation. The inclusion of $\mathrm{HO}$ records in the evaluation was expected to benefit BS sires with a large number of crossbred calvings, as well as BS sires whose daughters have HO contemporaries. The joint evaluation used the same sire and MGS birth-year group definitions as the routine $\mathrm{HO}$ evaluation and groups included sires of both breeds. Different groups were not used for each breed due to the small number of BS sires and similar trends over birth years in individual breed datasets. Groupings by breed may be necessary in the future to account for differing amounts of selection pressure on calving ease.

The approach used to calculate $\% \mathrm{DBH}$ was modified to account for breed-of-MGS effects. Van Tassell et al. (2003) computed \%DBH as:

$$
\begin{gathered}
1-\% \mathrm{DBH}^{*}=\overline{\mathrm{F}\left(\mathrm{T}_{3}-\varepsilon^{*}+\mathrm{c}\right)} \\
\% \mathrm{DBH}=1-\left[-\varepsilon+\mathrm{F}^{-1}\left(1-\% \mathrm{DBH}^{*}\right)+\overline{\varepsilon^{*}}\right]
\end{gathered}
$$

where $\mathrm{F}=$ standard normal cumulative density function, $\mathrm{T}_{3}=$ the threshold between $\mathrm{CE}$ scores of 3 and 4 on the observed scale, $\varepsilon=$ the solution on the underlying scale with fixed MGS birth year and breed-of-MGS solutions added to the MGS solution, and * denotes the group of animals used to define the base. A constant, $\mathrm{c}$, is used to achieve the desired base, and $\mathrm{c}$ in [2] is replaced with $\varepsilon$ in [3]. In a single-breed evaluation, $\varepsilon$ consists only of the random MGS solution plus the fixed MGS birth-year group solution. In a multiple-breed evaluation, $\varepsilon$ should be computed as the sum of the random MGS solution, the fixed MGS birth year solution, and the fixed breed-of-MGS solution.

\section{RESULTS}

Sufficient numbers of BS and JE records were available to provide exploratory evaluations for $\mathrm{CE}$ in those breeds. Further examination showed that BS records came mostly from herds that also provided HO records, suggesting that a joint BS-HO evaluation might be desirable. Too few Ayrshire, Guernsey, and Milking Shorthorn calvings ( 2573,5118 , and 1407 , respectively) were available to provide accurate evaluations for those breeds.

Distributions of calving ease scores by data set are presented in Table 1. The purebred and crossbred datasets had similar distributions of scores within sire breeds and very different distributions between sire breeds. Jersey sires produced calves that resulted in fewer difficult births (CE scores $\geq 4$ ) than did BS sires. Brown Swiss sires produced calves with higher frequencies of difficult births than JE sires but with slightly lower frequencies than HO sires. Similar trends were seen in score distributions by parity. In all breeds, the frequency of difficult births was highest in first parity. The difference between first and second parity was much greater than the difference between second and later parities.

Number of sires of each breed that received an evaluation is shown in Table 2. Sires of other breeds appear in the $\mathrm{BS}_{\mathrm{p}}, \mathrm{HO}$, and $\mathrm{JE}_{\mathrm{p}}$ datasets, e.g., $\mathrm{HO}$ and $\mathrm{JE}$ in the $\mathrm{BS}_{\mathrm{p}}$ data set, because some dams had a sire of a different breed. Holstein was the second most-frequent breed of sire in all datasets. In all cases, the 2 most frequent sire breeds accounted for more than $98 \%$ of the sires evaluated. These data suggest using a fixed effect which distinguishes between $\mathrm{BS}(\mathrm{JE}), \mathrm{HO}$, and all other breeds to account for breed-of-dam differences in the $\mathrm{BS}_{\mathrm{c}}\left(\mathrm{JE}_{\mathrm{c}}\right)$ data set is adequate.

\section{Preliminary Evaluations}

Brown Swiss. Distribution of CE scores by parity for the crossbred BS data set is shown in Table 3. Re- 
Table 2. Number of sires of each breed receiving an evaluation in the Brown Swiss, Jersey, and Brown Swiss-Holstein datasets.

\begin{tabular}{|c|c|c|c|c|c|c|c|}
\hline \multirow[b]{2}{*}{ Dataset $^{1}$} & \multicolumn{6}{|c|}{ Breed $^{2}$} & \multirow{2}{*}{$\begin{array}{l}\text { Number } \\
\text { of sires }\end{array}$} \\
\hline & $\mathrm{AY}$ & BS & GU & $\mathrm{HO}$ & JE & MS & \\
\hline $\mathrm{BS}_{\mathrm{p}}$ & 0 & 639 & 0 & 80 & 9 & 1 & 729 \\
\hline $\mathrm{BS}_{\mathrm{c}}$ & 3 & 641 & 2 & 1424 & 18 & 2 & 2090 \\
\hline $\mathrm{JE}_{\mathrm{p}}$ & 1 & 6 & 1 & 128 & 1860 & 1 & 1997 \\
\hline $\mathrm{JE}_{\mathrm{c}}$ & 11 & 14 & 18 & 2051 & 1868 & 3 & 3965 \\
\hline $\mathrm{BH}$ & 35 & 676 & 59 & 42,298 & 379 & 29 & 43,476 \\
\hline
\end{tabular}

${ }^{1} \mathrm{BS}_{\mathrm{p}}\left(\mathrm{JE}_{\mathrm{p}}\right)=$ Brown Swiss (Jersey) purebred calvings only; $\mathrm{BS}_{\mathrm{c}}\left(\mathrm{JE}_{\mathrm{c}}\right)=$ Brown Swiss (Jersey) purebred and crossbred calvings; $\mathrm{BH}=$ Brown Swiss purebred calvings, Holstein purebred calvings, and Brown SwissHolstein crossbred calvings.

${ }^{2} \mathrm{AY}=$ Ayrshire, $\mathrm{BS}=$ Brown Swiss, GU = Guernsey, HO = Holstein (includes Red and White sires), JE = Jersey, MS = Milking Shorthorn.

sults from the purebred evaluation (data not shown) were very similar. As expected, more difficult births were in first than in later parities. For first parity, difficult calvings were more frequent in the $\mathrm{BS}_{\mathrm{c}}$ data set $(6.0 \%)$ than in the $\mathrm{BS}_{\mathrm{p}}$ data set (5.1\%). Van Tassell et al. (2003) reported $8.1 \%$ calving difficulty in firstparity HO. Difficult births were less frequent in second and later parities for both breeds, with BS having fewer problems than HO. There was very little difference between CE scores in second vs. third and later lactations.

Statistics of solutions to the S-MGS model for the crossbred BS evaluation are presented in Table 4. Characteristics of the solutions are similar to results from the purebred evaluation (data not shown) and the routine HO evaluation (Van Tassell et al., 2003). The range and SD of the herd-year solution is smaller than for $\mathrm{HO}$, and is much larger than for any other effect. This lower variation may reflect the fact that many more herd-years are in the HO data than in either BS data set, resulting in fewer BS herds with extreme solutions resulting from the extreme category problem (Harville and Mee, 1984; Misztal et al., 1989). Sire and MGS birth-year group effects are small and consistent with the lack of genetic trend for \%DBH shown in Figure 1.

The distribution of service sire and daughter \%DBH for the crossbred evaluation is shown in Figure 2. The mode for $\mathrm{SCE}$ and $\mathrm{DCE}$ in $\mathrm{BS}_{\mathrm{p}}$ is $8 \%$, which matches results for purebred $\mathrm{HO}$ sires. The same mode is observed for $\mathrm{SCE}$ in $\mathrm{BS}_{\mathrm{c}}$, but the mode for DCE is 7. Both distributions have fewer sires with high \%DBH than those reported for HO (Van Tassell et al., 2003). In both datasets, the distribution of DCE is more compact than that of SCE, which is expected, because the genetic variance of DCE is smaller than that of SCE.

Distributions of the reliability of service sire and daughter \%DBH for both traits in both datasets are heavily right-skewed and reflect lower progeny numbers than are desirable from the perspective of genetic

Table 3. Distribution of calving ease scores in the Brown Swiss, Jersey, and Brown Swiss-Holstein datasets by parity.

\begin{tabular}{|c|c|c|c|c|c|c|c|c|c|}
\hline \multirow[b]{3}{*}{$\begin{array}{l}\text { CE } \\
\text { Score }^{1}\end{array}$} & \multicolumn{9}{|c|}{ Dataset $^{2,3}$} \\
\hline & \multicolumn{3}{|c|}{$\mathrm{BS}_{\mathrm{c}}$} & \multicolumn{3}{|c|}{$\mathrm{JE}_{\mathrm{c}}$} & \multicolumn{3}{|c|}{$\mathrm{BH}$} \\
\hline & First & Second & $\begin{array}{l}\text { Third } \\
\text { and } \\
\text { later }\end{array}$ & First & Second & $\begin{array}{l}\text { Third } \\
\text { and } \\
\text { later }\end{array}$ & First & Second & $\begin{array}{l}\text { Third } \\
\text { and } \\
\text { later }\end{array}$ \\
\hline 1 & 74.9 & 83.9 & 83.9 & 92.4 & 95.7 & 95.5 & 62.0 & 79.2 & 80.5 \\
\hline 2 & 10.5 & 8.0 & 8.0 & 4.5 & 3.0 & 3.0 & 15.1 & 9.0 & 9.4 \\
\hline 3 & 8.5 & 4.9 & 4.3 & 2.0 & 0.9 & 0.9 & 14.9 & 7.6 & 7.0 \\
\hline 4 & 3.1 & 1.3 & 1.8 & 0.6 & 0.2 & 0.3 & 5.2 & 2.2 & 2.0 \\
\hline 5 & 2.9 & 1.6 & 1.9 & 0.5 & 0.2 & 0.3 & 2.8 & 1.1 & 1.1 \\
\hline Total $^{4}$ & 20.2 & 28.7 & 51.1 & 28.1 & 25.0 & 46.8 & 26.0 & 29.5 & 44.5 \\
\hline
\end{tabular}

${ }^{1}$ Calving ease scores are: $1=$ no problem, $2=$ slight problem, $3=$ needed assistance, $4=$ considerable force, 5 = extreme difficulty. Calving ease scores of 4 and 5 were combined into a single score of 4 for each Jersey evaluation.

${ }^{2} \mathrm{BS}_{\mathrm{c}}\left(\mathrm{JE}_{\mathrm{c}}\right)=$ Brown Swiss (Jersey) purebred and crossbred calvings; $\mathrm{BH}=$ Brown Swiss purebred calvings, Holstein purebred calvings, and Brown Swiss-Holstein crossbred calvings.

${ }^{3}$ Tabled values are frequency $(\%)$ within dataset.

${ }^{4}$ Within-dataset totals. 
Table 4. Number of levels of effects, ranges, and SD of solutions from sire-maternal grandsire (MGS) threshold model equations.

\begin{tabular}{|c|c|c|c|c|c|c|c|c|c|}
\hline \multirow[b]{3}{*}{ Effect } & \multicolumn{9}{|c|}{ Dataset $^{1}$} \\
\hline & \multicolumn{3}{|c|}{$\mathrm{BS}_{\mathrm{c}}$} & \multicolumn{3}{|c|}{$\mathrm{JE}_{\mathrm{c}}$} & \multicolumn{3}{|c|}{$\mathrm{BH}$} \\
\hline & Levels & Range & SD & Levels & Range & SD & Levels & Range & $\mathrm{SD}$ \\
\hline Herd-year & 2026 & 3.89 & 0.39 & 3404 & 4.03 & 0.41 & 231,218 & 7.07 & 0.56 \\
\hline Year-season & 12 & 0.95 & 0.26 & 12 & 0.91 & 0.23 & 50 & 0.42 & 0.09 \\
\hline Parity-gender & 6 & 0.88 & 0.32 & 6 & 0.54 & 0.21 & 6 & 1.04 & 0.40 \\
\hline Sire birth year & 6 & 0.15 & 0.05 & 6 & 0.13 & 0.05 & 17 & 0.12 & 0.03 \\
\hline MGS birth year & 11 & 0.75 & 0.22 & 5 & 0.14 & 0.05 & 33 & 0.08 & 0.02 \\
\hline Breed composition & 3 & 0.34 & 0.17 & 3 & 0.49 & 0.25 & 3 & 0.08 & 0.04 \\
\hline Sire & 3422 & 0.48 & 0.03 & 6767 & 0.45 & 0.03 & 133,935 & 1.30 & 0.07 \\
\hline MGS & 3422 & 0.49 & 0.03 & 6767 & 0.38 & 0.03 & 133,935 & 0.85 & 0.06 \\
\hline
\end{tabular}

${ }^{1} \mathrm{BS}_{\mathrm{c}}\left(\mathrm{JE}_{\mathrm{c}}\right)=$ Brown Swiss (Jersey) purebred and crossbred calvings; $\mathrm{BH}=$ Brown Swiss purebred calvings, Holstein purebred calvings, and Brown Swiss-Holstein crossbred calvings.

evaluation. This is likely because a few bulls have a large number of records available, which gives high reliabilities, but most bulls have a very small number of daughters and receive correspondingly low reliabilities. In addition, Van Tassell et al. (2003) also reported that there is a consistent upward bias due to a simplifying assumption used in the computation of the reliabilities, that all relatives and contemporaries are perfectly evaluated, although most sires still have lower reliabilities
(46 to $50 \%$ ). The implementation of a routine national genetic evaluation for calving ease should result in an increase in the number of BS records reported from National Association of Animal Breeders progeny test herds. An increase in records should result in higher reliabilities for bulls.

Jersey. Distributions of CE scores by parity for the purebred (data not shown) and crossbred (Table 3) JE datasets indicated more difficult births in first than

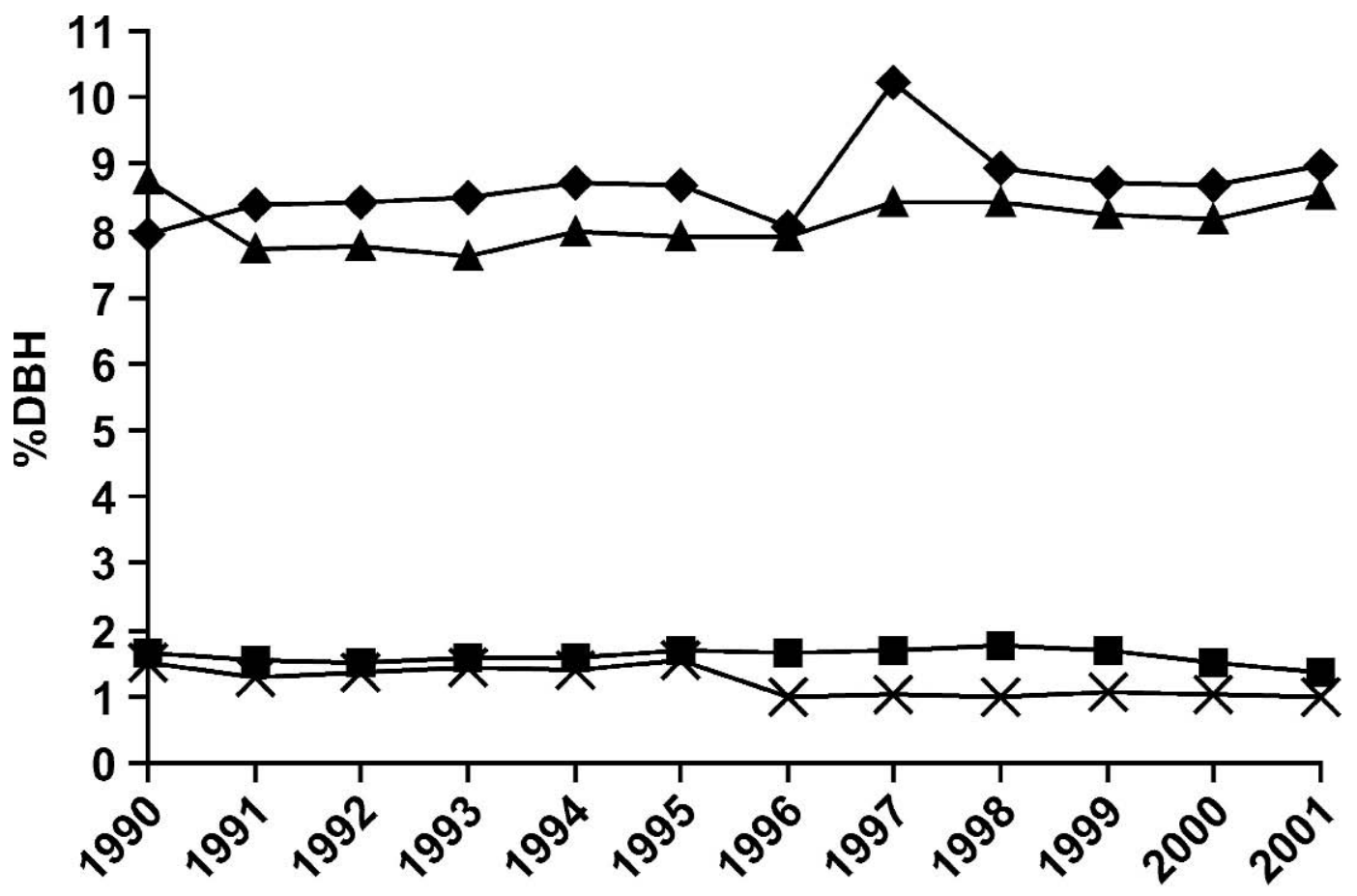

Birth year

Figure 1. Mean Brown Swiss service sire $(\diamond)$ and daughter $(\boldsymbol{\Delta})$ PTA and Jersey service sire $(\boldsymbol{\square})$ and daughter $(x)$ PTA for the percentage of births that are difficult for purebred and crossbred calvings of heifers (\%DBH) by birth year of bull. 


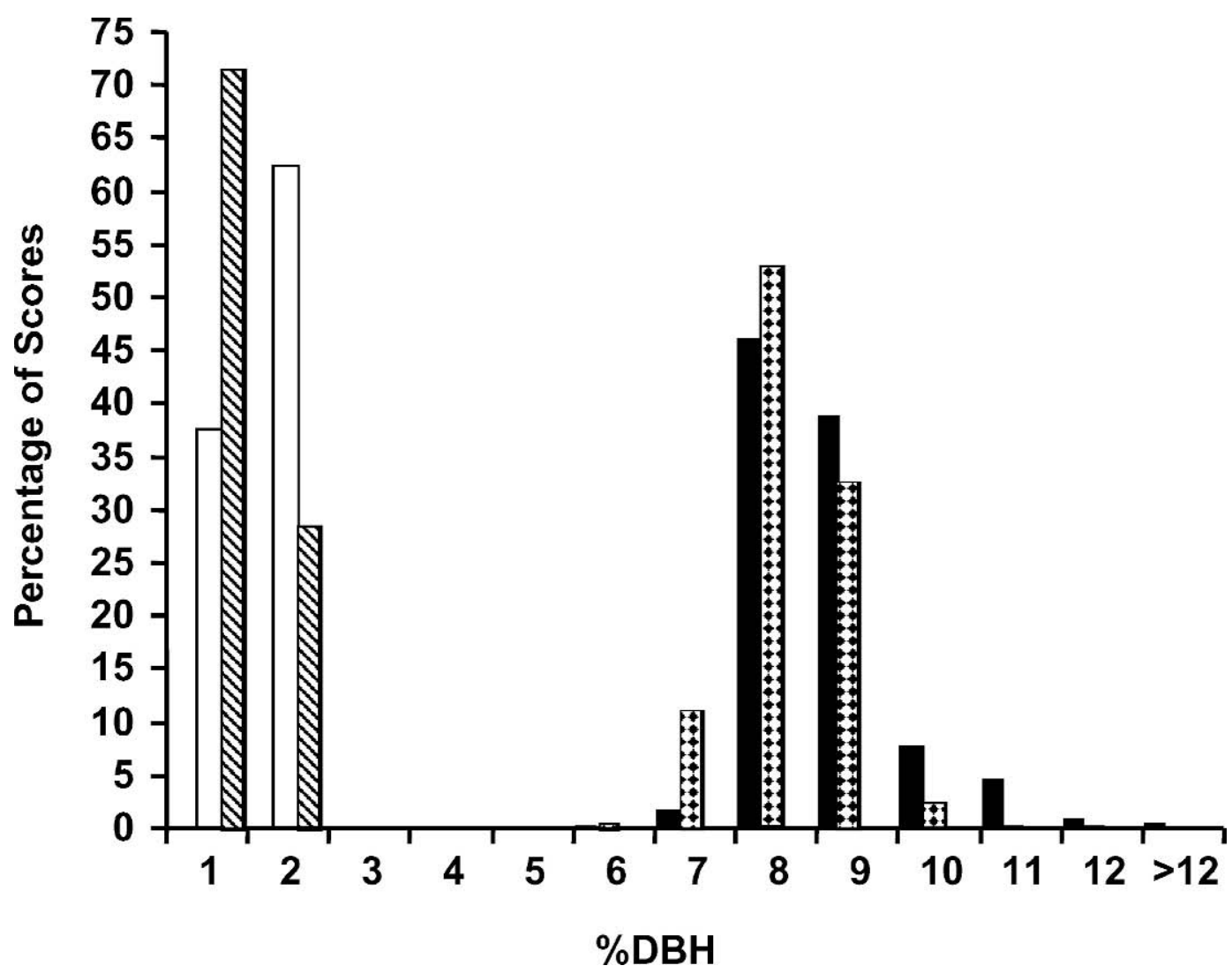

Figure 2. Distribution of all Jersey service sire (open) and daughter (diagonals) PTA and Brown Swiss service sire (solid) and daughter (checkered) PTA for the percentage of births that are difficult for purebred and crossbred calvings of heifers $(\% \mathrm{DBH})($ within-breed percentages sum to $100 \%)$.

later parities. For first parity, the incidence of calving difficulty (scores of 4 or 5 ) in the $\mathrm{JE}_{\mathrm{c}}$ data set was $1.1 \%$, the highest value for any parity in either data set. Scores of 1 (no problem) were recorded for more than $92 \%$ of all calvings. This is consistent with evidence that JE are easy calvers (Thompson et al., 1981). Statistics of solutions to the S-MGS model for the crossbred JE evaluations are presented in Table 4 . The range and SD of the solutions are similar to results from the purebred JE evaluation (data not shown) and the routine HO evaluation (Van Tassell et al., 2003), although the range and SD of the herd-year solution is smaller than for HO. This may reflect the fact that there was a greater number of herd-years in the $\mathrm{HO}$ data than either JE data set. The sire and MGS birth-year group effects are consistent with the lack of genetic trend for $\%$ DBH (Figure 1).

Distributions of service sire and daughter $\% \mathrm{DBH}$ (Figure 2) indicated \%DBH of 2 and 1 are most common for SCE and DCE, respectively, in the $\mathrm{JE}_{\mathrm{c}}$ data set. Only 2 JE bulls had a PTA $>2$ for SCE, and only one had a PTA $>2$ for DCE. No JE bull had a PTA $>3$ for any trait in either data set. Clearly, relative to other breeds, there are very small genetic differences among JE sires and MGS for either SCE or DCE. There are adequate $\mathrm{CE}$ data available in both breeds for genetic evaluation. Although there is sufficient genetic variability in the BS to make a routine genetic evaluation worthwhile, that is not the case with the JE.

\section{Joint Brown Swiss-Holstein Evaluation}

Results of the BS and JE evaluations indicate that routine evaluation of BS sires is possible. Many BS records come from herds that also provide $\mathrm{HO}$ records, and $\mathrm{F}_{1}$ calvings with non- $\mathrm{HO}$ sires and $\mathrm{HO}$ dams have reduced dystocia as compared with purebred HO calvings, suggesting that a joint evaluation using both the BS and HO data is desirable. The Netherlands (Interbull, 2004b) and New Zealand (Interbull, 2004c) use records from multiple breeds in a joint evaluation in their national genetic evaluations for $\mathrm{CE}$.

Genetic evaluation. Distribution of $\mathrm{CE}$ scores by parity for the $\mathrm{BH}$ data set is shown in Table 3. Difficult births accounted for $8,3.3$, and $3.1 \%$ of all calvings in first, second, and third parities, respectively. Scores of 


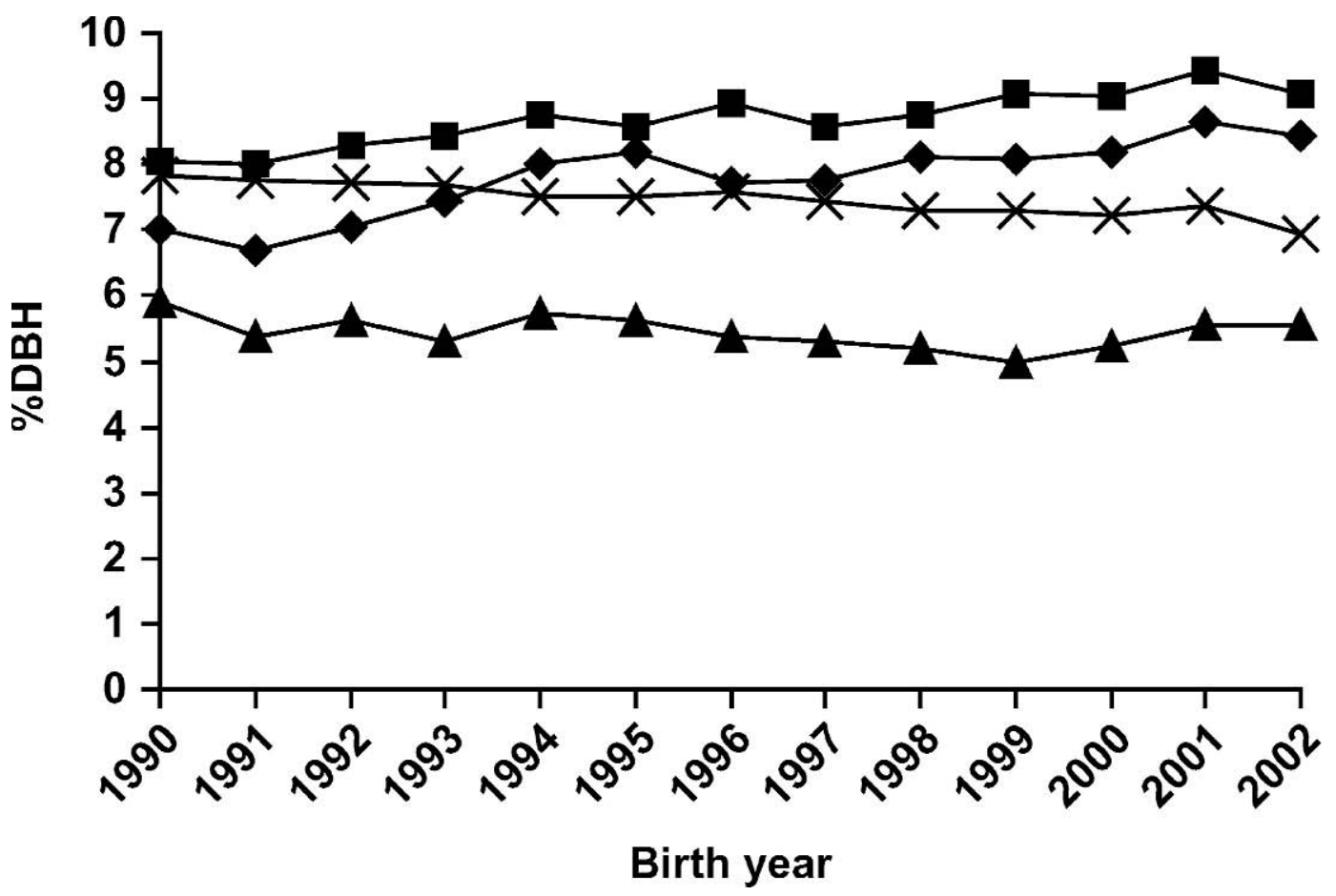

Figure 3. Mean Brown Swiss (BS) service sire $(\diamond)$ and daughter $(\boldsymbol{\Delta})$ PTA and Holstein (HO) service sire $(\mathbf{\square})$ and daughter $(\times)$ PTA for the percentage of births that are difficult for purebred and crossbred first-calf heifers (\%DBH) by birth year of bull from the joint evaluation.

4 and 5 occurred more often in this data set than in the $\mathrm{BS}_{\mathrm{c}}$ and had frequencies similar to the routine $\mathrm{HO}$ evaluation (data not shown). Addition of BS data to HO data did not change the distribution of scores. Statistics of solutions to the S-MGS model for the joint evaluation are presented in Table 4 and are very similar to reported results (Van Tassell et al., 2003). The range of the herdyear solution is larger than that reported for Holsteins in Van Tassell et al. (2003) but is comparable to the value (7.06) obtained in the routine August $2004 \mathrm{HO}$ evaluation. The sire and MGS birth-year group effects are consistent with the lack of genetic trend for \%DBH presented in Figure 3. Breed-of-MGS solutions were small (BS: -0.51 , HO: -0.55 , other: -0.48 ) and consistent with expectations; smaller values are more favorable.

Distributions of service sire and daughter $\% \mathrm{DBH}$ are shown in Figure 4. Brown Swiss appear to be a more desirable maternal breed than $\mathrm{HO}$, where most common $\% \mathrm{DBH}$ is 6 compared with 8 in HO. The difference between breeds is smaller for SCE, with most frequent $\% \mathrm{DBH}$ of 7 and 8 for BS and HO, respectively. The BS and $\mathrm{HO}$ bases for DCE are very similar (7.57 vs. $7.55 \%$ ) which suggests the observed difference is not an artifact of the evaluation procedure.

Distributions for service sire and daughter \%DBH reliability are shown in Figure 5. The reliability approx- imation used does not account for number of herdmates; therefore, the BS reliabilities do not directly reflect additional information provided by HO herdmates. Sire reliabilities are based solely on the magnitude of the diagonal element of the coefficient matrix corresponding to a given sire:

$$
\operatorname{rel}_{i, t}=1-\frac{\operatorname{diag}_{i, t}}{\sigma_{\mathrm{t}}}
$$

where rel $_{i, t}$ is the reliability of sire $i$ for trait $t$ (sire or MGS effect), $\operatorname{diag}_{i, t}$ is the reciprocal of the diagonal element from the coefficient matrix, and $\sigma_{\mathrm{t}}$ is the genetic standard deviation of trait $t$. The approximation assumes that all relatives and fixed effects in the model are perfectly estimated. Because of this assumption, $\mathrm{rel}_{\mathrm{i}, \mathrm{t}}$ computed in [4] is independent of the number of contemporaries. Berger (1994) showed sire model evaluation of calving ease requires a large number of effective progeny to achieve high reliabilities. Given the simplification used in [4], a larger number of effective progeny is probably required under the S-MGS model than a sire model. Although an improved method for computing reliabilities is desirable, it may not be of great practical significance. Berger (1991) found that all of the reliability approximations reviewed overestimated prediction error variances but were highly correlated with 


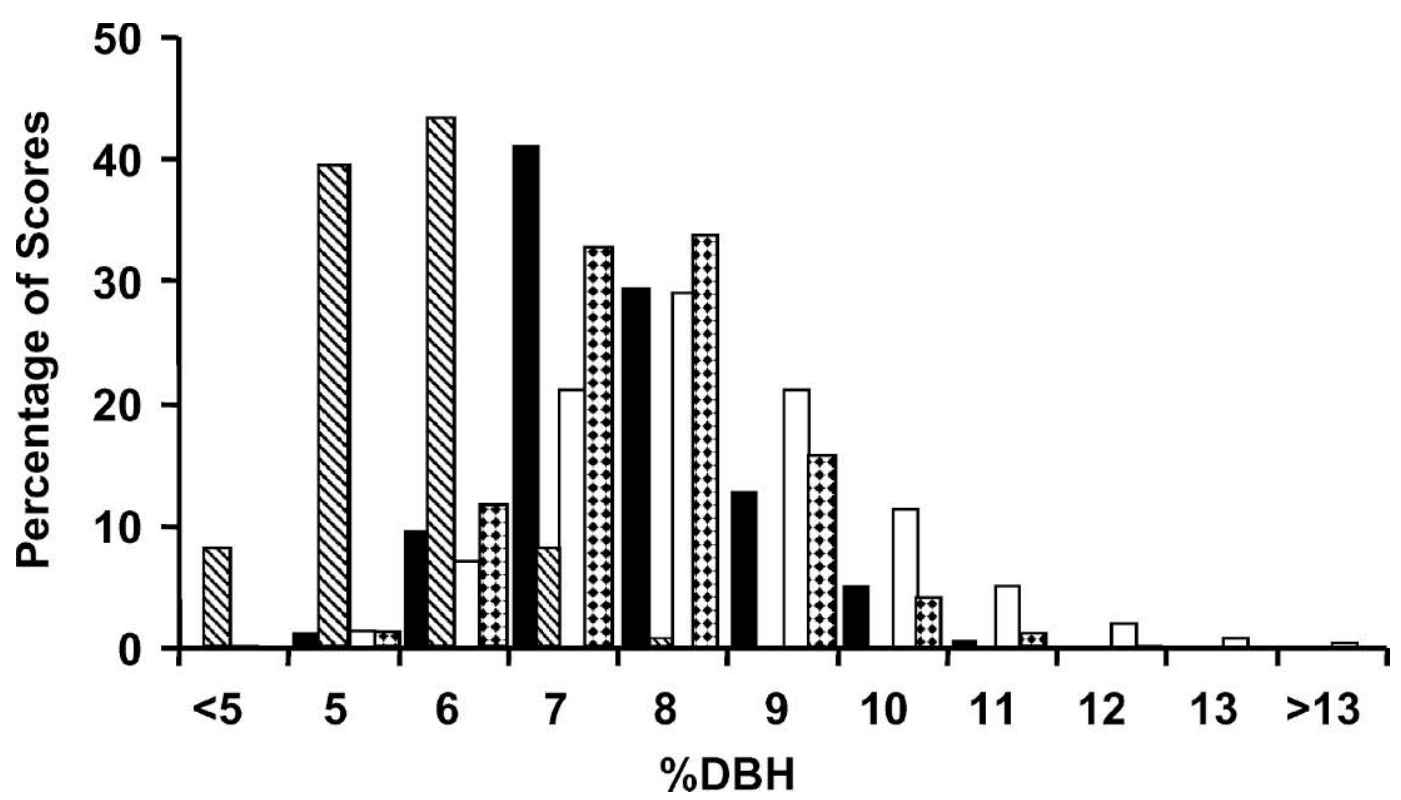

Figure 4. Distribution of all Brown Swiss (BS) service sire (solid) and daughter (diagonals) PTA and Holstein (HO) service sire (open) and daughter (checkered) PTA for the percentage of births that are difficult for purebred and crossbred calvings of heifers (\%DBH) from the joint evaluation.

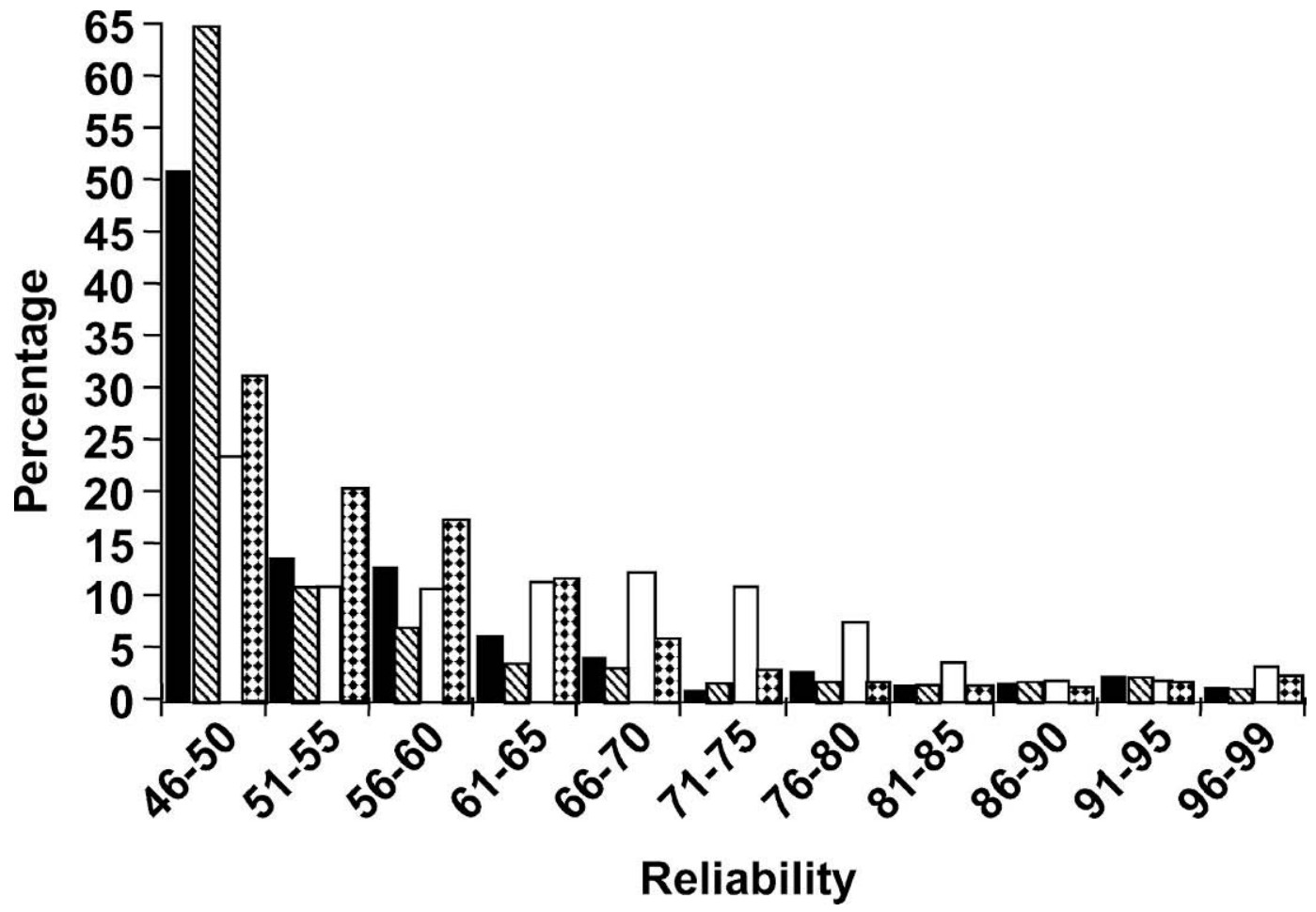

Figure 5. Distributions of reliabilities (\%) for Brown Swiss (BS) service sire (solid) and daughter (diagonals) PTA and Holstein (HO) service sire (open) and daughter (checkered) PTA for the percentage of births that are difficult for purebred and crossbred calvings of heifers $(\% \mathrm{DBH})$ from the joint evaluation. 
Table 5. Product-moment and rank correlations among sire-maternal grandsire (MGS) model solutions and PTA of Brown Swiss and Holstein sire and daughter calving ease from single-breed and joint evaluations.

\begin{tabular}{|c|c|c|c|c|c|c|c|c|}
\hline \multirow[b]{2}{*}{ Breed $^{1}$} & \multicolumn{4}{|c|}{ Product-moment correlations } & \multicolumn{4}{|c|}{ Rank correlations } \\
\hline & $\mathrm{Sol}^{2}$ & MGS Sol ${ }^{3}$ & $\mathrm{PDB}^{4}$ & MGS PDB $^{5}$ & Sol & MGS Sol & PDB & MGS PDB \\
\hline $\mathrm{BS}$ & 0.949 & 0.889 & 0.844 & 0.795 & 0.900 & 0.827 & 0.816 & 0.779 \\
\hline $\mathrm{HO}$ & 0.999 & 0.999 & 0.999 & 0.999 & 0.999 & 0.999 & 0.992 & 0.970 \\
\hline
\end{tabular}

${ }^{1}$ Breed of sire: BS = Brown Swiss, HO = Holstein (includes Red and White sires).

${ }^{2}$ Sire solution on the underlying scale.

${ }^{3}$ MGS solution on the underlying scale.

${ }^{4}$ PTA for sire calving ease reported as percent difficult births in heifers.

${ }^{5} \mathrm{PTA}$ for daughter calving ease reported as percent difficult births in heifers.

true prediction error variances. As long as reliabilities are consistently overestimated and selection pressure on $\mathrm{CE}$ remains low, consequences of this overestimation are minimal.

Validation. The joint evaluation was validated by comparing results with those from the $\mathrm{BS}_{\mathrm{c}}$ and routine HO evaluations. Brown Swiss records made up less than $0.15 \%$ of total records evaluated and therefore should have little impact on HO evaluations. Productmoment correlations among service sire and daughter evaluations (Table 5) confirm notable changes in service sire and daughter evaluations for BS sires with negligible changes for HO sires. Rank correlations were similar to product-moment correlations in all cases. Characteristics of the changes in solutions and PTA between the single-breed and joint evaluations are presented in Table 6. Brown Swiss evaluations changed moderately for both traits when moving from the single-breed to the joint evaluation; some reranking of sires also occurred. Changes in BS rankings are attributable to changes in sire and MGS solutions as well as sire and MGS birth year solutions.

Evidence of some minor reranking among HO sires exists for daughter calving ease, and is attributable to a rounding step used when solutions are converted from the underlying scale to the reported scale. Three bulls changed by 2 points, the greatest observed change, and all were sires with no direct calving records in the data set. The rank correlation is sensitive to small changes in PTA because the range of values for DCE is smaller than for SCE.

Genetic trend validation (Boichard et al., 1995) was performed on the $\mathrm{BS}_{\mathrm{c}}$ and $\mathrm{BH}$ datasets (results not shown). Method 3 validation, which compares sire evaluations over time as daughter records are added, was used. There should be no systematic change in sire PTA over time. The $\mathrm{BS}_{\mathrm{c}}$ validation did not produce a significant result due to the small amount of data available. The $\mathrm{BH}$ data set passed trend validation using the specifications provided by Interbull (Interbull, 2004a).

\section{DISCUSSION}

The available BS and JE data come largely from herds that also report HO calvings. This is consistent with the idea that many producers who crossbreed do so using HO heifers to reduce calving difficulty. There is a risk that these data do not represent truly random

Table 6. Summary of properties of changes in sire-maternal grandsire (MGS) model solutions and PTA for sire and daughter calving ease of Brown Swiss and Holstein sire and daughter calving ease from singlebreed and joint evaluations.

\begin{tabular}{llllllll}
\hline & \multicolumn{3}{c}{$\mathrm{BS}^{1}$} & & \multicolumn{3}{c}{$\mathrm{HO}^{2}$} \\
\cline { 2 - 3 } Trait & Mean & SD & Range & & Mean & SD & Range \\
\hline Sol $^{3}$ & -0.06 & 0.02 & 0.15 & & 0.01 & 0.002 & 0.09 \\
MGS Sol $^{4}$ & -0.12 & 0.03 & 0.24 & & 0.003 & 0.01 & 0.08 \\
PDB $^{5}$ & -1.15 & 0.63 & 4.00 & & 0.02 & 0.17 & 2.00 \\
MGS PDB $^{6}$ & -2.34 & 0.60 & 5.00 & & -0.07 & 0.26 & 3.00 \\
\hline
\end{tabular}

${ }^{1} \mathrm{BS}=$ Brown Swiss.

${ }^{2} \mathrm{HO}=$ Holstein (includes Red and White sires).

${ }^{3}$ Sire solution on the underlying scale.

${ }^{4}$ MGS solution on the underlying scale.

${ }^{5}$ PTA for sire calving ease reported as percent difficult births in heifers.

${ }^{6} \mathrm{PTA}$ for daughter calving ease reported as percent difficult births in heifers. 
samples from their respective breed populations. However, results obtained in this study seem to be reasonable and there are no values in the literature for comparison.

It was assumed the true values of (co)variance components used in the analysis were the same for all breeds and were equal to $\mathrm{HO}$ (co)variances (Wiggans et al., 2003). This seems reasonable for BS and HO, but may not be valid for JE. If this assumption is incorrect, the (co)variances used are probably overestimates for the JE population. The PTA from the JE analyses are very small, and if overestimated should not result in erroneous conclusions. Results suggest essentially no genetic variation exists for calving ease in the JE breed whether the heritability in the model was correct.

Heterosis was not directly accounted for in the crossbred evaluations. However, only $\mathrm{F}_{1}$ were included in the $\mathrm{BS}_{\mathrm{c}}, \mathrm{JE}_{\mathrm{c}}$, and $\mathrm{BH}$ datasets. The breed composition effects in the $\mathrm{BS}_{\mathrm{c}}$ and $\mathrm{JE}_{\mathrm{c}}$ models were equivalent to a heterosis effect with two levels, $0 \%$ (for purebreds) and $100 \%$ (for $\mathrm{F}_{1}$ ) because they distinguished between purebred and crossbred calvings. The breed composition effect used in the $\mathrm{BH}$ analysis differentiated between different breeds of MGS. Although this is not directly equivalent to general heterosis, it does account for some of the same variation because the model only considers purebreds and $\mathrm{F}_{1}$. If the joint evaluation model is extended to accommodate crossbreds other than $\mathrm{F}_{1}$, it will be necessary to include a covariate to account for general heterosis (VanRaden, 1992). This is a less sophisticated approach than the crossbred model proposed by Lo et al. (1997), but Lutaaya et al. (2002) found that the use of a crossbred model in swine is not justified when the evaluation of purebreds is the principal goal and the number of crossbred records is small relative to the number of purebred records. It is reasonable to assume the same would be true for dairy cattle.

The reliability approximation currently used does not increase when the number of daughter herdmates increases. A key argument in favor of developing a joint evaluation is that BS sires with many crossbred daughters, and whose crossbred daughters are found predominantly in HO herds, benefit from the inclusion of those data in the evaluation. There is substantial reranking of $\mathrm{BS}$ sires when comparing the $\mathrm{BS}_{\mathrm{c}}$ and $\mathrm{BH}$ evaluations, suggesting the joint evaluation does impact $\mathrm{BS}$ sires. Distributions of reliabilities from the $\mathrm{BS}_{\mathrm{c}}$ and $\mathrm{BH}$ evaluations were very similar for BS bulls.

The development and implementation of a routine national CE evaluation for BS bulls allowed the US to contribute those data to the international $\mathrm{CE}$ evaluation under development by Interbull. Contribution of BS data to the Interbull effort is desirable because US sires provide pedigree connections among several European populations.

\section{CONCLUSIONS}

Jerseys had very little calving difficulty and thus a very small range of evaluations. This is consistent with anecdotal evidence which suggests that JE rarely experience calving difficulty. There may be some genetic variation on the underlying scale that translates to little observed variation because the JE base is so small. The implementation of a routine national genetic evaluation for CE would not provide JE breeders with a useful tool for genetic improvement.

A joint evaluation for calving ease of $\mathrm{BS}$ and $\mathrm{HO}$ in the US has been developed. The joint evaluation utilizes information from purebred and crossbred (BS-HO) calvings of BS bulls, as well as purebred calvings of $\mathrm{HO}$ bulls. The joint evaluation does not adversely affect $\mathrm{HO}$ sires but does result in reranking of BS bulls as compared with an evaluation of BS data only. Evaluations from data for the August 2004 run were provided to Interbull for inclusion in the international pilot run for calving ease.

\section{ACKNOWLEDGMENTS}

The authors are grateful to Jeff Berger and Kent Weigel for valuable comments and discussion. The comments and suggestions of 2 anonymous reviewers are greatly appreciated.

\section{REFERENCES}

Berger, P. J. 1991. Reliability of sire evaluations for calving ease in a threshold model analysis. J. Dairy Sci. 74:1069-1077.

Berger, P. J. 1994. Genetic prediction for calving ease in the United States: Data, models, and use by the industry. J. Dairy Sci. 77:1146-1153.

Boichard, D., D. Bonaiti, A. Barbat, and S. Mattalia. 1995. Three methods to validate the estimation of genetic trend for dairy cattle. J. Dairy Sci. 78:431-437.

Cassell, B. G., K. E. Getzewich, R. L. Nebel, R. E. Pearson, S. T. Franklin, and A. J. McAllister. 2004. Early results of HolsteinJersey crossbreeding at Virginia Tech and Kentucky. J. Dairy Sci. 87(Suppl. 1):284. (Abstr.)

Harville, D. A., and R. W. Mee. 1984. A mixed-model procedure for analyzing ordered categorical data. Biometrics 40:393-408.

Heins, B. J., L. B. Hansen, and A. J. Seykora. 2004. Comparison of first-parity Holstein, Normande-Holstein crossbred, Montbeliarde-Holstein crossbred and Scandinavian-Holstein crossbred cows for dystocia and stillbirths. J. Dairy Sci. 87(Suppl. 1):282. (Abstr.)

Heins, B. J., L. B. Hansen, and A. J. Seykora. 2003a. Comparison of first-parity Holstein, Holstein-Jersey, and Holstein-Normande crossbred cows for dystocia and stillbirths. J. Dairy Sci. 86(Suppl. 1):130. (Abstr.)

Heins, B. J., A. J. Seykora, L. B. Hansen, J. G. Linn, D. G. Johnson, and W. P. Hansen. 2003b. Effect of mating Holstein females to Holstein versus Jersey AI sires on fertility, dystocia, calf weight, and retained placenta. J. Dairy Sci. 86(Suppl. 1):130. (Abstr.) 
Interbull. 2004a. Interbull Trend Validation Procedure. Available: http://www-interbull.slu.se/service_documentation/General/ trendvalid_web.pdf. Accessed Sept. 10, 2004.

Interbull. 2004b. Description of National Genetic Evaluation System (The Netherlands). Available: http://www-interbull.slu.se/ national_ges_info2/forms/nld/form_ca_nld_all_021220.pdf. Accessed Sept. 22, 2004.

Interbull. 2004c. Description of National Genetic Evaluation System (New Zealand). Available: http://www-interbull.slu.se/ national_ges_info2/forms/nzl/form_ca_nzl_all_030117.pdf. Accessed Sept. 22, 2004.

Lo, L. L., R. L. Fernando, and M. Grossman. 1997. Genetic evaluation by BLUP in two-breed terminal crossbreeding systems under dominance. J. Anim. Sci. 75:2877-2884.

Lutaaya, E., I. Misztal, J. W. Mabry, T. Short, H. H. Timm, and R. Holzbauer. 2002. Joint evaluation of purebreds and crossbreds in swine. J. Anim. Sci. 80:2263-2266.

McClintock, S., B. Kevin, M. Wells, and G. Michael. 2004. Calving difficulty in Holsteins and Jerseys and their crossbreds. J. Dairy Sci. 87(Suppl. 1):284. (Abstr.)
Misztal, I., D. Gianola, and J. L. Foulley. 1989. Computing aspects of a nonlinear method of sire evaluation for categorical data. J. Dairy Sci. 72:1557-1568.

Thompson, J. R., A. E. Freeman, P. J. Berger, and M. L. Martinez. 1981. A survey of dystocia and calf mortality in five dairy breeds. J. Dairy Sci. 64(Suppl. 1):81. (Abstr.)

Van Tassell, C. P., G. R. Wiggans, and I. Misztal. 2003. Implementation of a sire-maternal grandsire model for evaluation of calving ease in the United States. J. Dairy Sci. 86:3366-3373.

VanRaden, P. M. 1992. Accounting for inbreeding and crossbreeding in genetic evaluation of large populations. J. Dairy Sci. 75:3136-3144.

VanRaden, P. M., and A. H. Sanders. 2003. Economic merit of crossbred and purebred US dairy cattle. J. Dairy Sci. 86:1036-1044.

Weigel, K. A., and K. A. Barlass. 2003. Results of a producer survey regarding crossbreeding on US dairy farms. J. Dairy Sci. 86:4148-4154.

Wiggans, G. R., I. Misztal, and C. P. Van Tassell. 2003. Calving ease (co)variance components for a sire-maternal grandsire threshold model with calving ease data. J. Dairy Sci. 86:1845-1848. 